\title{
Implementation of $\alpha$-Sutte Indicator to Forecasting Consumer Price Index in Turkey
}

\author{
Ansari Saleh Ahmar ${ }^{1}$, Abdul Rahman ${ }^{2}, \&$ Usman Mulbar $^{2}$ \\ ${ }^{1}$ Departement of Statistics, Universitas Negeri Makassar \\ ${ }^{2}$ Departement of Mathematics, Universitas Negeri Makassar \\ email: ansarisaleh@unm.ac.id
}

\begin{abstract}
$\alpha$-Sutte Indicator ( $\alpha$-Sutte) was originally from developed of Sutte Indicator. Sutte Indicator can using to predict the movement of stocks. As the development of science, then Sutte Indicator developed to predict not only the movement of stocks but also can forecast data on financial, insurance, and time series data. This method called $\alpha$-Sutte Indicator ( $\alpha$-Sutte). $\alpha$ Sutte was developed using the principle of the forecasting method of using the previous data. The data used in this research is Consumer Price Index and Indices by Regions (Turkey) data from January 2003 - June 2017. This data is divided into 2 parts, namely training data and test data. Training data starts from January 2003 - October 2016 and test data from November 2016 - June 2017. To see the accuracy of $\alpha$-Sutte, it will be done benchmarking the results of forecasting with other forecasting method is Automatic Time Series Forecasting: The forecast Package for R (AutoARIMA) developed by Hyndman-Khandakar (2008). Comparison of this accuracy is to compare the value of MSE forecasting result on test data by using training data as reference data. Results obtained from this study that the MSE value of $\alpha$-Sutte is smaller (5.697723) than MSE from AutoARIMA (292.5125). This indicates that $\alpha$-Sutte is more suitable for predicting Consumer Price Index and Indices by Regions (Turkey) data.
\end{abstract}

Presented in:

International Conference On Mathematics and Natural Sciences 2017

6th - 7th September 2017

at Harris Sunset Road, Bali, Indonesia

Theme:

Encountering Global Challenge through Innovation on Science, Technology, Engineering, Mathematics (STEM) and Education 


\section{Introduction}

\section{Sutte \\ Indicator}

2015

Predicting the movement of Stock

\section{$\alpha$-Sutte}

Indicator

\section{7}

\section{Predicting the data}

Ahmar, A. S., Rahman, A., Arifin, A. N. M., \&

Ahmar, A. A. 2017. Predicting movement of stock of

" $\mathrm{Y}$ " using Sutte indicator. Cogent Economics \&

Finance, 1347123.

Ahmar, A. S. 2017. Sutte Indicator: an Approach

to Predicting the Direction of Stock Market

Movement. Songklanakarin Journal of Science

and Technology (SJST).

\section{$\alpha$-Sutte Indicator}

$$
a_{t}=\frac{\alpha \frac{\Delta x}{A}+\beta \frac{\Delta y}{B}+\gamma \frac{\Delta z}{C}}{3}
$$

$$
\begin{aligned}
& \delta=a_{t-4} \\
& \alpha=a_{t-3} \\
& \beta=a_{t-2} \\
& \gamma=a_{t-1} \\
& \Delta x=\alpha-\delta=a_{t-3}-a_{t-4} \\
& \Delta y=\beta-\alpha=a_{t-2}-a_{t-3} \\
& \Delta z=\gamma-\beta=a_{t-1}-a_{t-2} \\
& A=\frac{\alpha+\delta}{2} \\
& B=\frac{\beta+\alpha}{2} \\
& C=\frac{\gamma+\beta}{2}
\end{aligned}
$$




\section{Research Method}
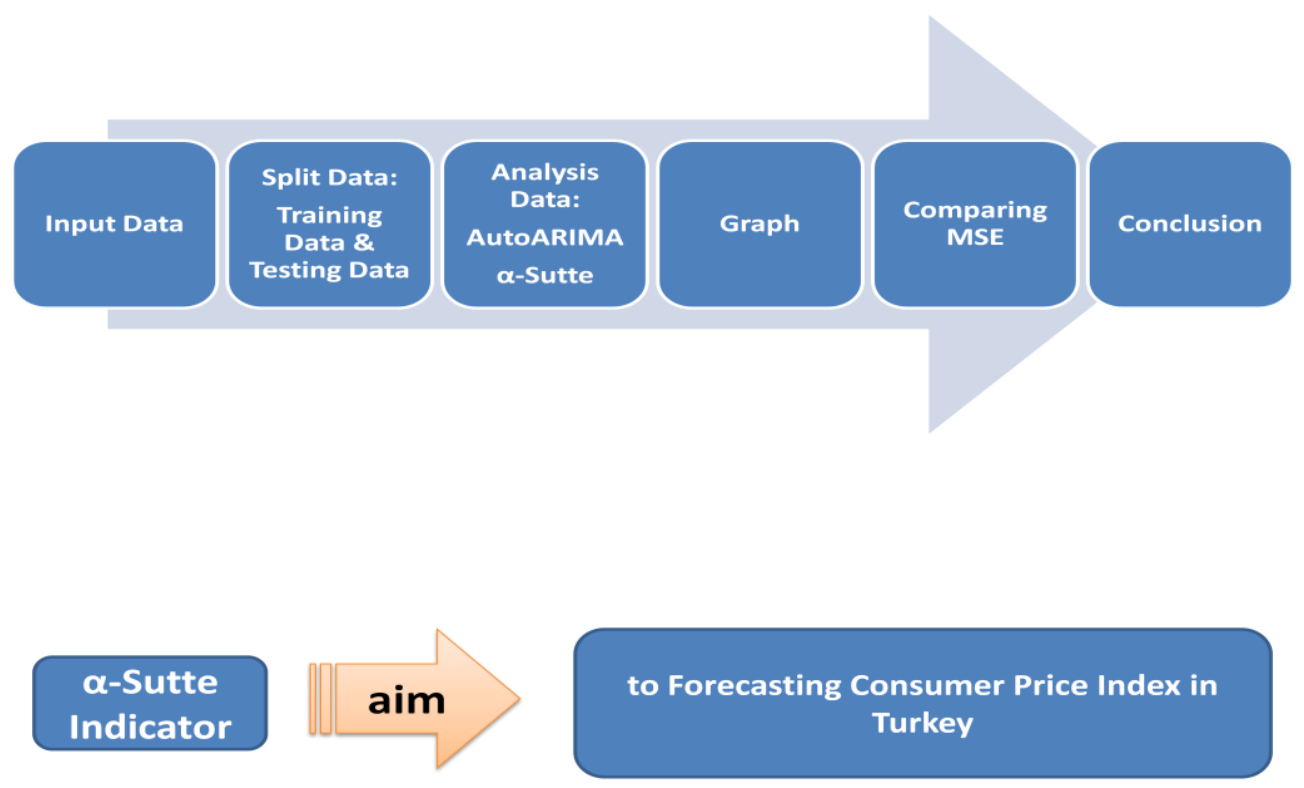

Consumer Price Index in Turki from TURKSTAT website

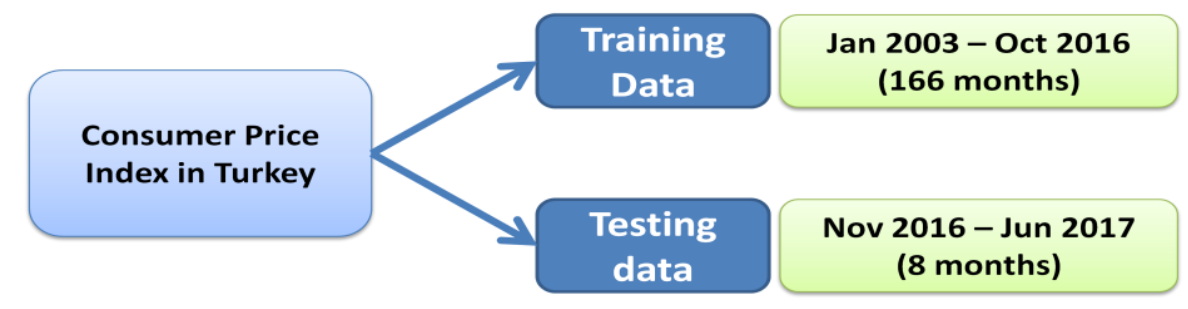

\section{Accuracy}

$\alpha$-Sutte Indicator

compare

Automatic Time Series

Forecasting: The forecast

Package for $\mathbf{R}$

(AutoARIMA)

Hyndman-Khandakar (2008)

\section{AR Method}

\section{HW-}

HW-Multiplicative
HW-Additive

Regression Seasonal

ARIMA
MSE (Mean Square of Error) 


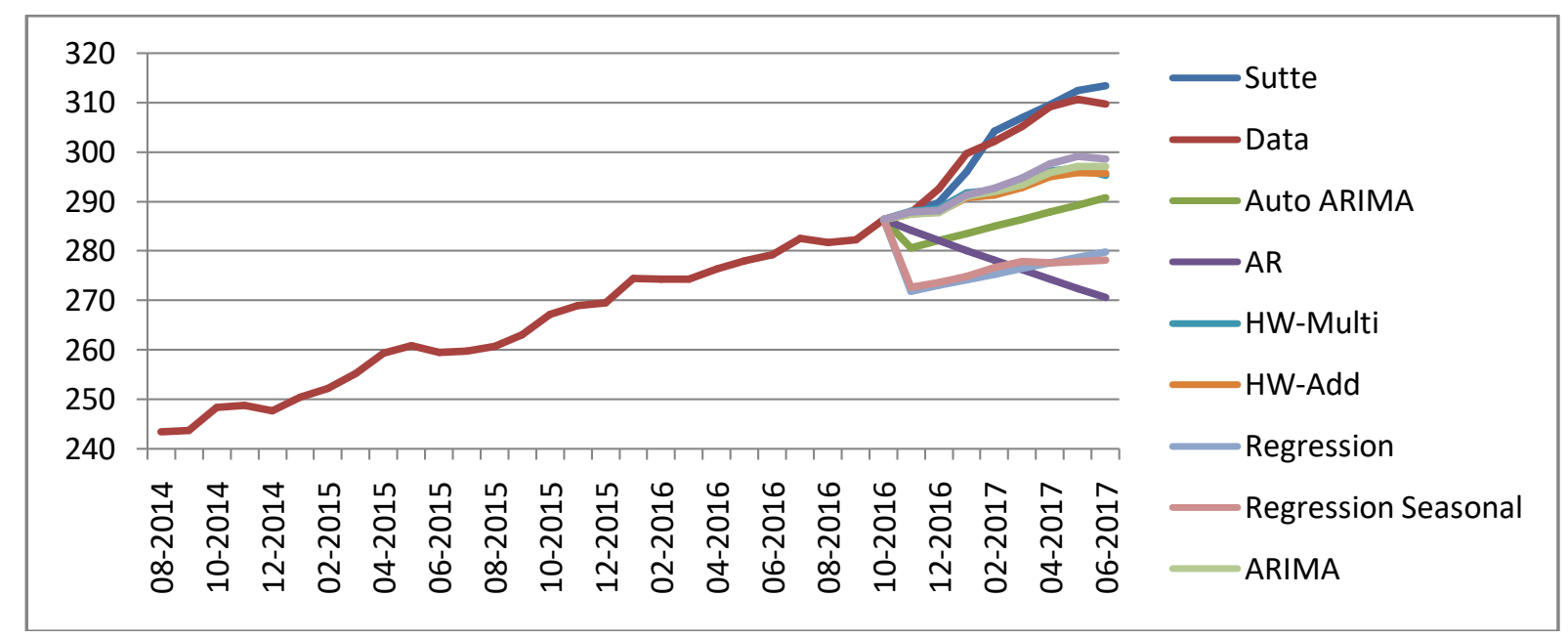

Comparison $\alpha$-Sutte with other Methods

\begin{tabular}{ccc}
\hline Type & MSE & RMSE \\
\hline AR & 768,17 & 27,72 \\
HW-Mul & 109,48 & 10,46 \\
HW-Add & 123,29 & 11,10 \\
Reg & 718,34 & 26,80 \\
Reg.seas & 709,59 & 26,64 \\
SARIMA & 108,09 & 10,40 \\
SARIMA.log & 84,82 & 9,21 \\
$\alpha-S u t t e$ & 5,70 & 2,39 \\
AutoARIMA & 292,51 & 17,10 \\
\hline
\end{tabular}

\section{Conclusion}

Results obtained from this study that the MSE value of $\alpha$-Sutte is smaller $(5,70)$ than MSE of other methods. This indicates that $\alpha$-Sutte is more suitable for predicting Consumer Price Index in Turkey.

\section{References}

Ahmar, Ansari Saleh, Sutte Indicator (December 7, 2015). Available at SSRN: https://ssrn.com/abstract=2846923 [Accessed April 14, 2016].

Ahmar, A.S. 2016. Predicting Movement of Stock of Apple Inc. Using Sutte Indicator. Proceedings The 3rd AISTSSE Trends in Science and Science Education, 2016. Available at SSRN: https://ssrn.com/abstract=2967947

Ahmar, A.S., 2017. Sutte Indicator: A Technical Indicator in Stock Market. International Journal of Economics and Financial Issues, 7(2).

Ahmar, A. S. 2017. SuIndiWeb: a web-based platform of sutte indicator to predicting movement of stock. Available at: http://eprints.unm.ac.id/2637/

Ahmar, A. S., Rahman, A., Arifin, A. N. M., \& Ahmar, A. A. 2017. Predicting movement of stock of "Y" using Sutte indicator. Cogent Economics \& Finance, 1347123.

Ahmar, A. S. 2017. Sutte Indicator: an Approach to Predicting the Direction of Stock Market Movement. Songklanakarin Journal of Science and Technology (SJST). 